https://doi.org/10.48075/odal.v0i0.28006

\title{
Representaciones de la identidad, la memoria y la historia: topónimos de los espacios públicos de Balsas, Maranhão
}

\section{Representation of identity, memory and recovery of History: toponyms of public places of the city of Balsas- MA}

\author{
Maria Célia Dias de Castro ${ }^{1}$ \\ http://orcid.org/0000-0003-3346-5990 \\ celialeitecastro@hotmail.com \\ Universidade Estadual do Maranhão (UEMA) \\ Marta Helena Facco Piovesan ${ }^{2}$ \\ https://orcid.org/0000-0002-1136-5991 \\ martahpiovesan@hotmail.com \\ Universidade Estadual do Maranhão (UEMA) \\ Traducido por Rigel Murrieta \\ https://orcid.org/0000-0002-1416-2495
}

Resumen: Los nombres propios de lugares, los topónimos, son elementos únicos del léxico de una lengua, los cuales, de entre sus diversas funciones como signo toponímico, sirven como huellas de la historia de los pueblos que los utilizan en sus interacciones verbales. Además, son verdaderos testimonios de los diferentes aspectos de la memoria y la identidad. Desde esta perspectiva, este trabajo tiene como principal objetivo comprobar cómo los topónimos de las aglomeraciones urbanas de Balsas, Maranhão, se manifiestan como representaciones de identidad, memoria e historia de sus habitantes. La metodología sigue los supuestos de la onomástica, en particular de la toponimia, con un análisis descriptivo de las categorías identidad y memoria, entrelazadas con la historia, las cuales se aplican a topónimos de índole antropocultural con base antroponímica, axiononímica, coronímica e historionímica. Los resultados revelan que los topónimos del sur de Maranhão expresan acepciones que abarcan la visión del mundo y la naturaleza y la visión de la vida humana y representan elementos memorísticos e identitarios de los diversos pueblos que habitan en esta localidad al establecer una relación con esas transposiciones y asignaciones lingüísticas.

Palabras clave: Topónimos, Identidad, Memoria, Historia, Balsas - MA.

\footnotetext{
${ }^{1}$ Doctora en Letras y Linguística (UFG). Profesora del “Departamento de Letras da Universidade Estadual do Maranhão" - UEMA/Campus de Balsas. Profesora del "Programa de Pós-Graduação em Letras da Universidade Estadual da Região Tocantina do Maranhão" - PPGLe - UEMASUL. Profesora colaboradora PPGEC MINTER/DINTER UNIJUÍ y UNIBALSAS. Coordinadora del proyecto ATEMA, Apoio FAPEMA.

${ }^{2}$ Doctora en Letras y Linguística (UNISINOS). Profesora de la Universidade Estadual do Maranhão UEMA/Campus de Balsas. Profesora investigadora del Proyecto "Atlas Toponímico do Maranhão" ATEMA.
} 


\begin{abstract}
The proper names of places, toponyms, are singular elements of the lexicon of the language that, among its various functions as toponymic sign, lend themselves as evidence of the history of the people who use them in their verbal interactions. In addition, they are true testimonies of the various aspects of memory and identity. With this perspective, Thus, this paper has as main aims to verify how the toponyms of the urban agglomerations of the city of Balsas-MA manifest the identity, memorable and historic representations of its inhabitants. The methodology follows the assumptions of onomastics, notably toponymy, with a descriptive analysis of the categories identity and memory intertwined with history, which are applied to toponyms of anthropocultural nature, with base axionimic, coronimic and historionimic toponyms. The results reveal that these toponyms in the south of Maranhão express the meanings that encompass the world view and the physical life and the human life view, which represent memorable and identity characters of the various peoples that inhabit this municipality, establishing proximity with these transpositions and institutions of the language.
\end{abstract}

Key-words: Toponyms, Identity, Memory, History, Balsas-MA.

\title{
1 Introducción
}

Al estudiar el léxico de una lengua, existe la posibilidad de recuperar aspectos lingüísticos, culturales e identitarios de una comunidad. También permite conocer las concepciones intrínsecas de la realidad en las que un determinado grupo se inserta. El estudio de los topónimos puede abonar al conocimiento de hechos históricos, características lingüísticas y de la etnología de la región que se quiere estudiar, así como al de los encuentros que constituyeron ese lugar. Para Dick (1980: 08), "la toponimia refleja fielmente la experiencia del hombre, como entidad individual y como miembro del grupo que lo acoge". La autora afirma que los topónimos son "verdaderos testimonios históricos" de los diferentes momentos de la vida de una población, que trascienden el acto de nombrar y que se convierten en un instrumento de proyección temporal que registra el presente para el conocimiento de las generaciones futuras. Se advierte que, además del tiempo vivido, son instrumentos de proyección humana, de la misma forma que atraviesan los más variados espacios geográficos.

A medida que los espacios se habitan, surge una necesidad del hombre de marcar su territorio y, para eso, a los lugares les asigna nombres que, a menudo, retratan aspectos históricos de territorialización y que, además, dejan ver características vinculadas a las creencias, la historia y la cultura de una comunidad. Los estudios onomásticos elucidaron la comprensión de los nombres de lugares y, por ello, fueron fundamentales para entender 
cómo se organizan y relacionan los grupos sociales en una intersección lingüística y sociocultural (BRANDÃO, ABBADE, 2016).

Balsas, ciudad ubicada al sur de Maranhão, tuvo una colonización muy diferente a la del litoral marañense, que fue colonizada por franceses, holandeses y portugueses y tuvo una gran influencia de negros africanos. El sur fue colonizado hasta después por vaqu,eros y ganaderos de otros estados de Brasil, como Piauí, Ceará y Pernambuco. Por la década de 1970, la región recibió una intensa corriente migratoria de Rio Grande do Sul y, después, de otras regiones de Brasil e incluso del exterior. Fue entonces, en este contexto de migración, entre la mezcla de personas, que surgió la ciudad de Balsas, cuyas redes de trabajo y estilos de vida locales fueron recreados y modificados.

Este nuevo contexto en la historia social de esta localidad planteó preguntas como: ¿cómo se perciben las representaciones de los sujetos denominadores?; ¿qué elementos constituyen los rasgos memorísticos de estos nombres?; ¿qué rasgos identitarios de los nombres de las aglomeraciones urbanas de la ciudad de Balsas, Maranhão, pueden comprobarse?

Como resultado de estas preguntas, en este artículo se presentan, tanto un enfoque teórico como aspectos centrados en el análisis, como sugieren Teis, Seide y Lucas (2018), de los topónimos que nombran las aglomeraciones del centro urbano de Balsas, Maranhão, con base en sus rasgos culturales y en las representaciones de la memoria y la historia como constructoras de las identidades de sus habitantes y, por consiguiente, con el estudio lingüístico anclado en una caracterización externa.

El corpus recopilado pertenece al catálogo de fichas lexicográficas que contiene los topónimos de los espacios públicos de la ciudad de Balsas, Maranhão. Estos topónimos fueron organizados, según Dick (1990), en 27 taxonomías, 11 de índole física y 16 de índole antropocultural. Se seleccionaron las siguientes categorías de índole antropocultural: antropotopónimos (nombres propios individuales: Cândido Mendes, Coelho Neto); axiotopónimos (títulos y tratamientos de respeto: Barão de Grajaú, Dom Pedro), corotopónimos (ciudades, países, estados, regiones: Alto Alegre do Maranhão, Alto Alegre do Pindaré); e historiotopónimos (nombres de hechos o personajes históricos: Bequimão, Carolina). Esta selección se hizo en el entendido de que este conjunto de nombres establece una relación más cercana con la cultura y la memoria. Así, estos 
nombres pasaron a ser parte del corpus del Atlas Toponímico do Estado do Maranhão ATEMA.

En este sentido, el estudio de topónimos aquí emprendido, al registrar hechos y acontecimientos de la formación de esa sociedad y además de identificar elementos físicos y humanos que constituyen los nombres de los espacios públicos de Balsas, se convierte en un testimonio histórico. Y la memoria es una propiedad muy significativa en la constitución de los lugares y de los nombres que los identifican.

\section{Lugares y memoria}

El término memoria, según Houaiss y Villar (2009), proviene del latín memoria, -ae y significa "facultad de preservar y recordar estados pasados de conciencia y todo cuanto haya asociado a ellos"; "lo que le sucede al espíritu como resultado de experiencias ya vividas, recuerdos, reminiscencias".

La memoria, según Le Goff (2003: 419), es la "propiedad de guardar cierta información; nos remite, en primer lugar, a un conjunto de funciones psíquicas, gracias a las cuales el hombre puede actualizar información o impresiones pasadas, o que él representa como pasadas". El autor (2003: 422) da cuenta de la ampliación de la noción de memoria y hace hincapié en el interés por el control de la memoria y el olvido, en el sentido de que ese hecho es "uno de los grandes intereses de las clases, grupos e individuos que han dominado y dominan las sociedades históricas. El olvido y los silencios de la historia revelan estos mecanismos de manipulación de la memoria colectiva". A propósito del transcurso de la historia, recuerda el interés que tenían las sociedades ágrafas por la memoria colectiva y dice que se ordenó en tres ejes: la edad colectiva del grupo, el prestigio de las familias dominantes y el conocimiento técnico.

Le Goff (2003) apunta que, en el Antiguo Oriente, por ejemplo, después de las grandes celebraciones como hechos delimitadores de la memoria, surgieron las estelas ${ }^{3} \mathrm{y}$ los monumentos simbólicos de la memoria, como el Naram-sin, en la ciudad de Susa, que simbolizaba el triunfo sobre los pueblos de Zagros, y la estela de Hammurabi, rey babilónico (1792 a 1750 a. C.), en la que impuso su conocido código y que forma parte

\footnotetext{
${ }^{3}$ Columna o placa de piedra sobre la que antiguamente se realizaban inscripciones, generalmente funerarias (HOUAISS, VILLAR, 2009).
} 
de la colección del Museo del Louvre de París. Como manifestación de la memoria, los recuerdos, en forma de inscripciones, se materializaron en templos, plazas, avenidas e incluso en las orillas de los caminos y llevaron a los griegos y a los romanos a tenerlos presentes a través de las celebraciones y la perpetuación. En la historización de Le Goff (2003), Goody presenta listas lexicales, glosarios y tratados de onomástica como instrumentos notables para el desarrollo de la memoria en las civilizaciones antiguas, partiendo del supuesto de que nombrar es conocer; por su lado, Gardiner habla sobre los antiguos tratados egipcios de onomástica que datan del 1100 a. C., probablemente inspirados en modelos sumerios. Con los griegos se produjo una evolución de la perspectiva de la memoria, en la que la memoria representa una invención, la conquista del hombre de su pasado individual y la forma en la que, para el grupo, la historia constituye una recuperación del pasado colectivo. Los griegos incluso hicieron de la memoria una diosa, Mnemosine, y Platón y Aristóteles entendieron la memoria como un componente del alma. Le Goff (2003) señala que, partiendo de la filosofía cristiana, existe una simbiosis entre muerte y memoria y que, en la Edad Media, se veneraba a los ancianos por que se les veía como guardianes de la memoria, lo que les confería mucho prestigio y utilidad. En el Antiguo Testamento, los libros de Deuteronomio (8:11; 8:14) e Isaías (44-21) invitan a los fieles a preservar la memoria, que representa el conocimiento de Yahvé. Desde el Antiguo hasta el Nuevo Testamento (la última cena), la memoria se presenta como una acción que invoca a Yahvé y conserva la tradición; el pueblo hebreo es considerado un pueblo de memoria por excelencia. San Agustín, en Confesiones, profundiza en la concepción de la memoria, de los lugares de la memoria, buscando a Dios en la entraña de su memoria, aunque sin encontrar ninguna imagen que lo personifique.

En la actualidad, la sociología explica la memoria bajo un nuevo concepto en el sentido de que, según Maurice Halbwachs (1950 apud LE GOFF, 2003: 466), está vinculada "a comportamientos, a mentalidades, nuevo objeto de la nueva historia". En este caso, Nora (1993) ve la memoria como las impresiones de lo experimentado por los grupos en el pasado o, incluso, de lo que los grupos hacen con aquello que vivieron en el pasado. Así, la memoria colectiva está rodeada de cuestiones sociales, de clases que son dominantes o no dominantes y de la forma en que esas clases se apropian de estos elementos en las luchas de poder y supervivencia. La memoria es, sin duda, instrumento 
y objeto de poder. Nora (1993: 09) discute la semejanza que hay entre memoria e historia y afirma que "mientras haya huella, distancia, mediación, ya no estamos dentro de la verdadera memoria, sino dentro de la historia". Por lo tanto, los indicios materiales que han sido registrados traspasan el nivel de la memoria, puesto que la memoria, para la gente, estaría humanizada, en movimiento, vitalizada dialógicamente entre el recuerdo y el olvido, con las debilidades a la que expone esta humanización: deformaciones sucesivas, vulnerabilidad a las manipulaciones, revitalizaciones repentinas y una reconstrucción problemática. La pérdida del recuerdo, de la memoria tradicional, conduce al desplazamiento y, retomando el objeto de estudio, esta pérdida del recuerdo, de la añoranza, impacta en las interrelaciones sociales, en el lenguaje y a través de él y conduce al surgimiento de nuevos términos.

Nora (idem) recuerda que la memoria tradicional va desapareciendo y esto obliga a que se acumulen distintos materiales: vestigios, testimonios, documentos, imágenes, discursos, señales que comprueben a los sujetos lo que existía en tiempos remotos.

Esta relación intrínseca tiempo-sujeto es de gran interés para Bergson (2006: 08), quien da una explicación sobre la duración del universo: “cuanto más profundizamos en la naturaleza del tiempo, más entendemos que duración significa invención, creación de formas, elaboración continua de lo absolutamente nuevo". Y toda esta creación y cambio transcurre en el espacio. La duración temporal es vista como movimiento, es decir, el tiempo del recuerdo, el tiempo de la memoria, mueve la materia psíquica y lingüística.

\footnotetext{
De hecho, el pasado se sostiene a sí mismo automáticamente. Sin lugar a duda, nos sigue por completo en todo momento: lo que sentimos, pensamos o queremos desde nuestra primera infancia está ahí, arrojado sobre el presente, del que saldrá al encuentro, forzando la puerta de la conciencia, a la que le gustaría dejarlo fuera. (...) A lo sumo, algunos recuerdos de lujo logran colarse por la puerta entreabierta (...). En efecto, ¿qué somos, qué es nuestra esencia, sino la condensación de la historia que hemos vivido desde nuestro nacimiento, o incluso desde antes, que llevamos con nosotros disposiciones prenatales? (BERGSON, 2006: 47-48, la cursiva es del autor).
}

Como una manera de ver la memoria, Bergson (2006: 48-49) se cuestiona si se trata de recuperar un recuerdo, un periodo de nuestra historia en el que nos alejamos del presente para reubicarnos en el pasado como si estuviéramos fotografiando ese pasado. Pero para Bergson (2006: 49), imaginar es no recordar. Él entiende el recuerdo como la actualización de una imagen que vuelve a la vida; pero la sola imagen no se refiere al pasado a menos que haya sido evocada del pasado. 
Como sugieren Le Goff, Nora y Bergson a propósito de la memoria, al escuchar nombres tomados de sujetos del pasado y de otros espacios, ocurre un movimiento en dirección de la imagen que estos nombres sugieren, en una circularidad imaginaria que se retroalimenta del recuerdo hacia la materialidad. Comprender estos movimientos no es privilegio de los filósofos del lenguaje. Un pasado que adquiere vida en el anclaje de los nombres lo logra percibir la gente común, la cual le da mucha importancia a este hecho y se apega a él para honrar sus memorias individuales y resocializarlas a través de los nombres de lugares.

Por lo tanto, la memoria de los sujetos o de un grupo se (r)establece de manera consistente en el acto de nombrar aglomeraciones humanas. La historia de los denominadores es recuperada del tiempo vivido en interrelación con los espacios en los que se ubican. Como puede verse, los topónimos son como hilos que se conectan entre sí en un espacio territorial y lengua dada y en una temporalidad, lo cuales, a su vez, están vinculados a factores externos, que también están vinculados a factores cognitivos y así, en una red de circularidad y complejidad, establecen su materialidad sistémica de la lengua.

\section{Lugares e identidad}

El término identidad es de origen latino (identitas, -ātis), formado a partir del adjetivo "idem", que significa "el mismo", y del sufijo -dade, que indica un estado o cualidad (Houaiss, Villar, 2009). Los procesos identitarios, en la actualidad, son ampliamente discutidos, principalmente en el campo de las ciencias sociales $\mathrm{y}$, más recientemente, con aportaciones de la Lingüística. La identidad es esencialmente conflictiva, involucra interacción social, emociones, autoestima y juegos de poder. Para Moreno (2014: 07) "la identidad es una categoría social construida discursivamente, expresada y percibida por diferentes lenguajes: escrito, corporal, gestual, imaginario, mediático". Más clara que la noción de cultura, la identidad implica la producción de discursos que porten signos de identificación. Un grupo con una cultura común no siempre se reconoce a sí mismo en discursos de identidad ni es objeto de ellos. Así, la identidad estaría vinculada a la representación de la cultura de uno o más grupos humanos. La identidad cultural está directamente vinculada a la definición de identidad, ya que es 
la identificación esencial de la cultura de un pueblo. Lo que un pueblo produce lingǘstica, religiosa, artística, científica, moral e históricamente forma parte de su capital cultural, el cual tiende a seguir ciertos patrones, lo que crea una forma de identidad para las culturas de determinadas sociedades.

La identidad es un proceso que surge de la interacción de los seres humanos, se construye socialmente y rechaza cualquier mirada relacionada con factores biológicos y categorizaciones sociales simplistas. Para Hall (2012), las identidades no definen individuos o grupos étnicos/nacionales específicos, sino que se muestran y negocian a través del trabajo discursivo en interacción con los otros. Esto reafirma el hecho de que las identidades no se ven como algo que las personas tienen, sino algo que las personas hacen en un proceso de autopresentación, de autoafirmación y de afirmación de su propia imagen frente al otro, una representación del yo histórico y cotidiano.

Las viejas identidades, que durante tanto tiempo estabilizaron el mundo, están en decadencia, afirma Hall (2012), lo que da lugar a nuevas identidades y fragmenta al individuo moderno, visto hasta entonces como un sujeto unificado. Surge, entonces, la llamada "crisis de identidad" debido a un inexorable proceso de cambio provocado por la globalización y la intensa migración humana. Las distancias han disminuido, la información viaja rápidamente y el hombre tiene la posibilidad de cruzar fronteras, buscar nuevos lugares e integrarse y conectarse con nuevas comunidades en nuevas combinaciones espaciotemporales.

Desde el punto de vista del surgimiento de nuevas identidades y la fragmentación del individuo, antes percibido como un ser unificado, recordemos que la región de Balsas, en el sur de Maranhão, locus de esta investigación, fue colonizada por migrantes y, posteriormente, en la década de 1970, sufrió una fuerte migración, principalmente de los sureños, que se intensificó en los años de 1980 y 1990 y que dio lugar a que se transformara en una frontera agrícola. Sandri y Baú (2008) señalan que fue en la década de 1970 que se produjo el mayor flujo de migración interna en Brasil debido a una política agraria favorable, por lo que los tres estados de la región del sur comenzaron una intensa migración en busca de tierras para el cultivo en los estados de Acre, Amazonas, Bahía, Goiás, Maranhão, Mato Grosso, Piauí y Rondônia. De esta manera, las migraciones ocurridas en Balsas están directamente relacionadas a la creación de nuevas fronteras 
agrícolas y, en consecuencia, de nuevas identidades sociales y identidades de los individuos, ya fueran migrantes o naturales de la región.

Las migraciones humanas desempeñan un papel importante en la construcción de sociedades híbridas, de las que emergen identidades culturales que no son fijas, sino que están en constante cambio y que son producto de complicados cruces y mezclas culturales que son cada vez más comunes en el mundo globalizado (HALL, 2012). Las migraciones posibilitan la formación de identidades que cruzan e intersectan fronteras naturales compuestas de personas que abandonan su patria y negocian con otras culturas. Los migrantes, que a veces continúan manteniendo vínculos con sus lugares de origen y tradiciones, negocian con las nuevas culturas en las que viven, sin asimilarlas plenamente y sin perder por completo sus identidades.

En este sentido, Canevacci (1996: 14) apunta el éxito de la perspectiva sincrética en la antropología, cuyo adjetivo disciplinar es la cultura que "ya no se ve como algo unitario, que compacta y reúne individuos, sexos, grupos, clases y etnias; sino que es algo mucho más plural, descentrado, fragmentario, conflictivo" y el sincretismo "es el resultado de un contacto intercultural e interlingüístico, por tanto, ubicuo, pidgin, criollo: es un contagio cultural, un virus" (idem). De esta manera, asume el concepto de sincretismo como una palabra clave fundamental para entender todas estas transformaciones que ocurren en la actualidad, con la propia globalización y localización, que impacta en los modos tradicionales de producción cultural.

Las sociedades construidas a partir de procesos migratorios no están unificadas, porque son producto de diversas historias y culturas; sin embargo, están interconectadas, son sincréticas.

También se puede pensar en la alteridad, noción que define al ser humano en una relación que toma en cuenta su diferencia con el otro. Para Castro (2012: 148), esta noción se ve en las interacciones con los nombres, que revelan la necesidad del hombre de “identificarse a sí mismo e identificar el espacio en el que vive, a través de las características étnicas que permiten distinguirlo, de forma individual o en grupo, de otras personas o lugares, y los individualizan en relación con otros grupos o individuos". En este sentido, la alteridad puede considerarse no como una oposición, sino como un elemento que está dentro de un grupo y que es constitutivo de la propia identidad. 
La identidad se entiende bajo el supuesto de la contemporaneidad, que se basa en la igualdad y la diferencia, dice Hall (2014) y que no es un fenómeno fijo e inmutable, sino una realidad dinámica en constante evolución. Los procesos de la construcción de la identidad no solo se dan al interior de las personas, sino que también se definen y demarcan a través de las relaciones con otros objetos pertenecientes a la colectividad y en los distintos ámbitos culturales en los que se insertan los individuos. Por lo tanto, la formación de la identidad está determinada por los contextos de cada colectividad, un proceso confiere características y valores propios de cada territorio. Son los procesos identitarios construidos de esta forma los que otorgan internamente personalidad y diferencia a cada lugar, dándole la autonomía que distingue y diferencia a los sujetos frente a los contextos globales uniformadores (HALL, 2012). Son estas características materiales e inmateriales de un territorio las que, aunque cambiantes, contribuyen a la (re)construcción de identidades y son fundamentales para dar originalidad y unicidad a los lugares y, en consecuencia, diferenciarlos de otros lugares y territorios.

Nombrar un lugar es una necesidad de ubicación, pero también es parte de la cultura del ser humano. Este acto está cargado de intenciones y sustenta las características físicas del entorno y las subjetividades de sus denominadores. De esta manera, los topónimos pueden representar valores, revelar rasgos culturales de la memoria e identidad de un pueblo a través de las particularidades cristalizadas en el término toponímico. El motivo para que esto suceda implica una compleja interacción entre las condiciones del individuo y el entorno en el que se encuentra (DICK, 1980: 42).

Así, el análisis de las relaciones existentes entre el lenguaje toponímico y la identidad del grupo que se apropia de él es un tema que merece ser señalado. Nombrar un espacio es un rasgo cultural indiscutible, por lo tanto, constructor y externalizador de identidades, pero también es una estrategia de poder, ya que es el resultado de las leyes implementadas por el poder público, que determinan la forma en que la denominación se llevará a cabo (Santos, 2020).

Nombrar lugares trae consigo una fuerza construida por el tiempo, pero también por la aceptación de quienes necesitan referirse a un lugar con un nombre que sea conocido por todos. Los seres humanos están sujetos al espacio y al tiempo, y las designaciones espaciales y temporales son una parte de la identidad, tanto como que el espacio es esencial para la supervivencia. Para Santos (2020: 613) “el lugar es el resultado 
de las experiencias humanas. Su existencia se explica por la forma en que la gente lo percibe y le da sentido". Existe una familiaridad entre los individuos y los espacios que los rodean, lo que provoca una carga subjetiva y una fuerte identificación entre el grupo y el topónimo.

La connotación geográfica de la identidad no se puede referir a la mera dimensión espacial del fenómeno identitario, sino que, por el contrario, se puede utilizar para representar los vínculos de pertenencia que crean "territorio". También vale la pena mencionar aquí el concepto de identidad geográfica como una "relación de identidad que vincula a una determinada comunidad con su espacio vivido" (CALDO, 1996: 285). Para el autor, "espacio vivido" debe entenderse como ese momento de integración que integra en su interior la dimensión física del espacio geográfico y la dimensión social del espacio relacional. El espacio no es solo un escenario de la acción humana, sino que también es un escenario cargado de los valores de la cultura que allí se produce.

También cabe agregar que la identidad territorial puede interpretarse como sentido de pertenencia, de identificación social y de representación compartida por un yo colectivo. Pertenecer a un territorio implica mucho más que nacer y vivir en él; implica, sobre todo, el establecimiento de relaciones sociales y la construcción de una identidad regional (PIOVESAN, 2020). Este sentimiento de pertenencia implica la construcción de una identidad cultural que incluya hábitos, creencias y tradiciones vinculadas a la vida cotidiana. Penna (2006) explica que el sentimiento de pertenencia surge precisamente de la articulación entre la identidad territorial y la identidad cultural. La necesidad de pertenencia, inclusión y arraigo es común, sobre todo, en el establecimiento de nuevas fronteras en las que se refleja un sentimiento de alteridad, de partícipes constitutivos de un todo que tienen los mismos motivos e intereses al de la comunidad que los constituye.

La función de intermediación de la memoria entre pasado y presente tiene un papel referencial importante para la (re)construcción de las identidades, en tanto que son construidas en la interacción, a partir de diferencias y negociaciones entre individuos ubicados en determinados lugares.

\section{Transitando por lugares e identidades (trans)plantadas}


Retomando a Moreno (2014), el autor sostiene que la identidad es una construcción social discursiva expresada en diferentes lenguajes, así como Le Goff (2003), que habla sobre la expansión de la noción de memoria y el interés de las clases, grupos e individuos que han dominado y dominan las sociedades históricas al controlar la memoria y el olvido.

¿A través de qué elementos lingüísticos se construyen discursivamente estas identidades y memorias?

Es el léxico, el rostro del lenguaje, el que permite producir discursos con la noción de cultura, identidad, memoria e historia, los cuales implican la producción de signos que portan tales nociones, y los signos lingüísticos con función toponímica se prestan perfectamente para este papel. Los topónimos de las aglomeraciones urbanas de Balsas, Maranhão, mencionados en este trabajo fueron seleccionados de las siguientes cuatro categorías (DICK, 1992): antropotopónimos, axiotopónimos, corotopónimos e historiotopónimos. A través de estos nombres de lugares se reconstruye el camino de la memoria, que trasciende a la historización gracias a la implementación y difusión de los nombres, desde los archivos de la memoria hasta la difusión social a través de la práctica del lenguaje. Esta práctica ocurre al incorporar los recuerdos repetidos de momentos representativos de vidas pasadas, de tal manera que atribuyen formas sistematizadas a los nuevos espacios habitados. Se hace uso de la emergencia de la memoria individual y de un grupo social, lo que significa, en palabras de Halbwachs, "que hay tantas memorias como grupos humanos; que es, por naturaleza, múltiple y desacelerada, colectiva, plural e individualizada" (2006 apud NORA, 1993: 09). La memoria es un elemento constitutivo del sentido de identidad, tanto individual como colectiva, ya que también es un factor extremadamente importante para el sentido de permanencia y coherencia de una persona o de un grupo en la reconstrucción de sí mismos (POLLAK, 1992).

Es posible notar que las diversas concepciones presentes en la materialización de la memoria, que aportan la vitalidad de los referentes que fueron incorporados a los nombres de los espacios públicos, están organizados en dos grupos ${ }^{4}$. En primer lugar, «el

\footnotetext{
${ }^{4}$ Esta macrocaracterización de los dos grupos se basa en Sapir (1980), quien entendía el conjunto de signos de la lengua como una forma compleja dentro de un marco físico y social en el que se organizan los grupos humanos. Dick (1990; 1992) se basó en esta orientación conceptual para organizar las 27 categorías con las que clasificó la toponimia brasileña, subdividida en dos grandes grupos, los de carácter físico y los de carácter antropocultural. En esta clasificación, se buscó enlistar aspectos que caracterizan el conjunto de topónimos que portan los rasgos referenciales más evidentes de la vida humana relacionados con la cultura
} 


\section{https://doi.org/10.48075/odal.v0i0.28006}

mundo y la vida física" (el mundo y la naturaleza), que incluye aspectos geofísicos y espacios ya habitadas. En segundo lugar, la vida humana, que abarca la dimensión religiosa, que incluye elementos del hombre, la religión y la fe; la dimensión política, que incluye elementos como el poder, privado y público, el individuo y la comunidad; la naturaleza humana, en la que se consideran aspectos como el carácter, la virtud, el error, el arte, la poesía; la justicia, que comprende leyes, normas, el orden, expresiones legales; la vida física humana, que incluye el estado físico hombre, los sentidos, la salud, la enfermedad; las acciones humanas, incluidas las buenas y las malas; las condiciones económicas, que toman en cuenta la riqueza y la pobreza; el conocimiento: ciencia, conocimiento, escuela, educación, y los movimientos humanos: migraciones y hechos históricos. Todos estos aspectos perceptibles de la materialización de la memoria se manifiestan a través del lenguaje y, de manera más notable, en antropotopónimos, axiotopónimos, corotopónimos e historiotopónimos, estableciendo una interrelación con los aspectos culturales e identitarios que constituyen al hombre, ubicado social y temporalmente en espacios geográficos.

Dentro de este conjunto, los apellidos se enlistan primero en nombres de lugares, que en la taxonomía de Dick (1990) se clasifican como antropotopónimos. Según Seabra (2004: 353), en áreas de (in)migración, las denominaciones de lugares suelen ser homenajes a personalidades de la clase política, así como a concejales municipales (vereadores). En el sur de Maranhão, este conjunto de nombres relaciona la vida humana con su dimensión política, que reúne áreas de las esferas del gobierno y del poder público conferido de una comunidad a un individuo. Esta relación la hace al incorporar, con el objetivo de denominar las calles, la memoria de los antiguos habitantes de la localidad, tales como: Vereador Manoel João de Bastos, Isaac Martins, Vereador Manoel Leite, Vereador Salvador Coelho, Vereador Constâncio Coelho, Vereador Antônio Pires, Vereador Aldemar, Vereador Homérico, Antônio Ribeiro da Silva, Vereador T. Alencar Sampaio, Vereador Cláudio Pires, Vereador José Silva de Oliveira; nombres de alcaldes (prefeitos): José Leão, Jorge Cury, Joaquim Coelho, Prefeito Lauro Maranhão; de presidentes: Presidente Prudente de Morais, José Sarney, Presidente Dutra e Juscelino.

\footnotetext{
y la identidad. Las microcategorizaciones se inspiraron parcialmente en el Dicionário de Sentenças Latinas
} e Gregas (TOSI, 1996). 
Onomástica Desde América Latina, n.4, v.2, jul - dez, 2021, p. 176-199. ISSN 2675-2719 https://doi.org/10.48075/odal.v0i0.28006

Los nombres de familiares de políticos también son recurrentes, como Francisco Martins Santos, Vicente Dourado da Silva. Estas denominaciones revelan una correlación con la conciencia de poder, el poder que tiene la memoria para extender el tiempo de los sujetos referidos y de los propios sujetos representados, por lo que presentan la necesidad de cambiar los nombres existentes por aquellos que incorporan la vida humana en la dimensión política.

Otro grupo muy representativo es el de los nombres de los ciudadanos que se sabe que tenían buena situación económica, que toman en cuenta la riqueza y la pobreza, en particular los que tienen muchos "posesiones", que sin duda estaban bien posicionados socialmente, como Edísio Silva, Gomes de Sousa, Passondas Coelho, Domingos Almeida, Roberto Maranhão, Gesner Soares, Arão Ferreira Lima, José Nunes Silva, Francisco Lima. Por el contrario, se observa una escasa incorporación de nombres de personas reconocidas, pero con una vida sencilla y con una condición económica que no se destaca por la riqueza, como Olavo C. Ribeiro, Eliezielda C. Rocha, Raimundo N. Almeida, Aprígio Alencar.

En las denominaciones se puede observar, sobre todo, una vuelta al pasado, una aprehensión de ese pasado, en un movimiento que se manifiesta en una imagen presente, como subraya Bergson (2006), al hacer que muchos de estos nombres salgan a la luz; es la presencia viva y al mismo tiempo simbólica de la memoria un movimiento hacia la historia, en el que ponderan «las memorias vagas, telescópicas, globales o flotantes, privadas o simbólicas" (NORA, 1993: 9), recuerdos sígnicos y sensibles que se trasladan y proyectan en los escenarios lingüísticos del presente. En este marco surgen los movimientos humanos, migraciones y hechos históricos, con nombres que representan el mito fundador o pionero del lugar, como Antônio Jacobina; nombres históricos tomados de la historia nacional y regional de los actuales habitantes de esta localidad: Tiradentes, Bento Gonçalves y Garibalde Nunes.

Nombres de escritores marañenses y brasileños también forman parte de este conjunto memorístico que representa la naturaleza humana, su carácter y sus virtudes a través del arte (la poesía) con escritores o poetas, como Humberto de Campos, João Pessoa, Cassemiro de Abreu, Coelho Neto, Castro Alves. Bergson (2006: 49) hace apuntes sobre la memoria y sus aspectos historizados y plastificados: 


\begin{abstract}
Poco a poco, aparece como una bruma que se condensa; de lo virtual pasa al estado actual y, a medida que se dibujan sus contornos y su superficie gana color, tiende a imitar la percepción. Pero permanece atada al pasado por sus profundas raíces, y si, una vez terminada, no se resintiera de su virtualidad original, si, al mismo tiempo que un estado presente, no fuera algo que contrastara con el presente, nunca la reconoceríamos como recuerdo [...] siguiendo, así, el progreso continuo que la llevó de la oscuridad hacia la luz.
\end{abstract}

Los nombres son de la historia misma y la historia, como afirma Nora (1993: 9), “es de todos y de ninguno, lo que le da vocación para ser universal. La memoria tiene sus raíces en el concepto, en el espacio, en el gesto, en la imagen, en el objeto. La historia sólo está vinculada a las continuidades temporales, a las evoluciones y a las relaciones entre las cosas”. Así, la transición y repetición de los nombres de lugares se procesan concomitantemente en el recuerdo y encarnan la identidad y la memoria a través del recuerdo y el reencuentro de los referentes que son personificadas y objetivadas, en las que los elementos de la lengua conducen al reencuentro de la identidad y la pertenencia por medio de la designación.

Algunos cuantos nombres de mujeres hacen su aparición: Milu Fonseca Santos, Emília Camera, Ritinha Pereira, nombres que historizan el papel que desempeñaron, que dejan huella de la escasa visibilidad que tenían en el contexto de una sociedad provinciana que se anticipó a los años del siglo XXI. Estas mujeres hicieron aportaciones al conocimiento, principalente en el ámbito de la educación, que se consideraron buenas acciones humanas, fructíferas y constructivas. En este conjunto toponímico se encuentran los nombres de los profesores Melquíades Moreira, Profa. Virgínia Kury y Profa. Maria Amélia Bezerra (quien aún reside en la ciudad). Con los nombres de estos profesores, la memoria renace mucho más viva, con una sensación de fascinante de praesentia colectiva.

Las personas reconocidas por su autoridad en la sociedad tienen sus nombres incorporados gracias a sus buenas obras en lo referente a la vida humana, en tanto al estado físico, salud y enfermedad, incluyendo los topónimos Dr. Didácio Santos y Dr. Rosy en este grupo. El reconocimiento a las buenas obras en el campo de la justicia, la ley y el orden están constatadas en los axiotopónimos Dr. Justo Pedrosa, Dr. Renato Carvalho, Capitão Borba, Duque de Caxias, Coronel Fonseca, Coronel Silva Neto, Soldado Bruzaca. Las buenas obras en la dimensión religiosa del hombre y la fe se incluyen en los axiotopónimos D. Diogo Parodi, Dom Rino Carlesi, Dom Pedrito, Padre Franco, cuyos nombres vienen a recordar un pasado que comienza a vivirse en un eterno 
presente (NORA, 1993), el lenguaje hace posible actualizar estas acciones como un fenómeno siempre presente.

Figura 1: Placa con axiotopónimos ubicada en el centro de Balsas, Maranhão

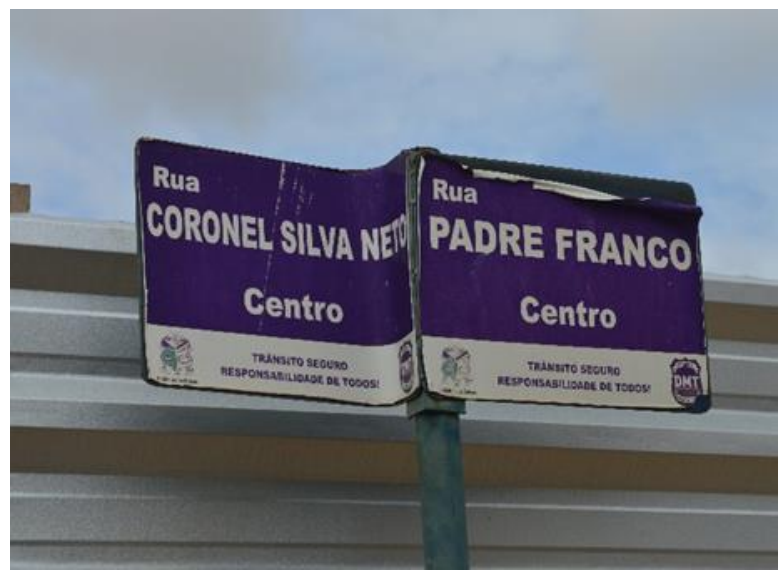

Fuente: las autoras.

Es curioso el papel que desempeñan los axiotopónimos en los referentes de la memoria, pues llevan la duración de los sujetos del pasado al presente, extendiendo el tiempo vivido de estos sujetos y perpetuándolos indefinidamente. Cuanto más atenta es la observación a la naturaleza del tiempo, más entendemos que su duración es también una invención, quiere decir, la creación de nuevas formas, explica Bergson (2006). Vale la pena recordar a los guardianes de la memoria de los que habla Le Goff, en el sentido de que gran parte de lo que se conoce, sobre todo acerca de estos axiotopónimos y antropotopónimos, se debe a ellos; de cierta manera, las personas mayores aún son vistas como hombres-memoria y este atributo les otorga un prestigio considerable.

¿Los topónimos del sur de Maranhão conllevan rastros de alteridad y sincretismo?

Se tiene en cuenta, en este trabajo, que la alteridad no se opone a la identidad, sino que la constituye, pues convive con la diferencia dentro de un grupo. Se considera que los topónimos representan los elementos y el ser del sujeto histórico: sus memorias, sus sentimientos, el espacio en el que vive o vivió, de manera que se distinga y se sienta parte de un grupo o un lugar, que sienta la relación pertenencia con otros grupos y lugares.

En las regiones con un proceso migratorio más reciente, la antropotoponimia manifiesta su intención de definir la posesión del territorio ocupado. En este proceso, el apellido se llena de una carga simbólica y social de poder, y la presencia de los nombres 


\section{https://doi.org/10.48075/odal.v0i0.28006}

de las personas en forma de topónimo es una forma de cristalizar, en el tiempo, el respeto por las personalidades y los grupos elegidos, así como sus acontecimientos como parte de la memoria colectiva del lugar (Philippsen, LIMA, 2018); una manera de cristalizar el respeto y admiración en el tiempo y el espacio. A partir de estas migraciones, muchos nombres de migrantes del sur se han atribuido a lugares públicos, como Dr. Irineu Alcides Bays, Leonardo Phillipsen y José Pugliesi.

Figura 2: Placa ubicada en el barrio de Fátima (Balsas, Maranhão) con antropotopónimos de origen alemán e italiano

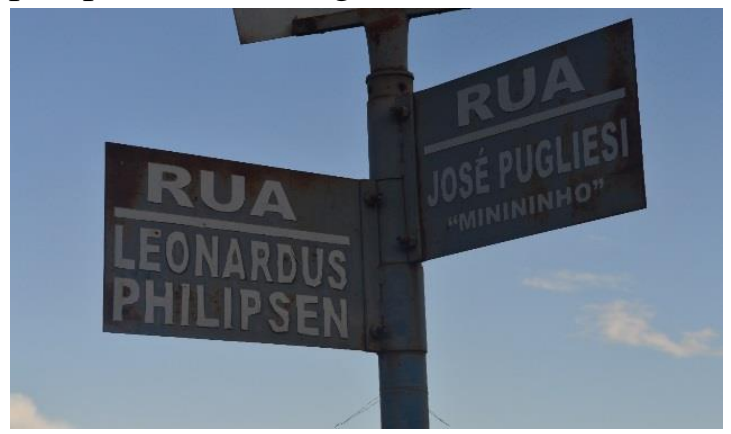

Fuente: las autoras.

También destacan las movilizaciones humanas a través de los procesos migratorios de los sirio-libaneses, representados en axiotopónimos como Profa. Virgínia Kury y Dr. Rosy Kury. Estos testimonios lingüísticos a través del léxico ratifican la posibilidad del hombre de atravesar fronteras, buscar nuevos lugares e integrarse socialmente en nuevos espacios. La atribución de estos nombres establece un compromiso identitario de los habitantes actuales con los espacios mediante el lenguaje, el cual los inserta e historiza en estos espacios. También existe el compromiso con el mundo y la naturaleza de esos sujetos cuando historizan sus espacios previamente habitados: acortan las distancias entre un allá y un aquí. Por lo tanto, se puede afirmar plenamente que el léxico da testimonio de la alteridad en los nombres toponímicos de las aglomeraciones urbanas de la ciudad de Balsas, Maranhão.

A este conjunto hay que añadir los corotopónimos de origen sureño que denominan espacios públicos: Rio Grande do Sul, Santa Catarina, Paraná, Caxias, Gramado, Passo Fundo, Canastra, Florianópolis, Caçapava, Cruz Alta, Bento Gonçalves, Vacaria, Santa Maria, Bagé, Uruguaiana, Canoas, Alegrete, Perolas, São Miguel, Rio Pardo, Santa Rosa y São Borja. El uso recurrente de esta categoría revela 
procesos identitarios, como afirma Hall (2012), que le otorgan personalidad y diferencia a la ciudad, dándole particularidad al distinguir y diferenciar tanto a la ciudad como a los sujetos que la habitan, pero también comprometiendo al hombre con sus referentes, su identidad, su historia y su memoria para compensar el cambio de espacio. O incluso, como nos recuerda Nora (1993), las huellas, la distancia y la mediación nos transportan, más allá de la memoria, más allá de la verdadera memoria, a la historia.

Tanto los corotopónimos como los nombres de migrantes del sur, como Dr. Irineu Alcides Bays, Leonardo Phillipsen, José Pugliesi, y de descendientes sirio-libaneses, Profa. Virgínia Kury y Dr. Rosy Kury, revelan, a través del léxico, una perspectiva sincrética de la cultura que, según Canevacci (1996: 14), no es unitaria, compacta, sino plural, descentrada; son nombres que resultan del contacto intercultural e interlingüístico.

La presencia de esta significativa cantidad de corotopónimos correspondientes al sur del país revela una negociación y una aceptación, una proximidad sociocultural, una convergencia cultural en el territorio en el que se ubican hoy. Estos nombres hacen más visibles los lugares que fueron transportados en la memoria y en la historia.

¿Habría un sentimiento de marginación en la historia oficial del lugar-presente que hiciera aparecer necesidad de recuperar su lugar-pasado, una necesidad de constitución en el espacio-pasado que llevaría a redescubrir sus orígenes en el espacioaquí y en el tiempo-ahora?

Los nombres-lugares no estarían en un lugar-aquí si un sujeto constituido cultural y conscientemente no hubiera decidido hacerse cargo de este trasplante hasta adaptar los espacios-memoria a espacios-nombre. Se trata de una recuperación de la conciencia, que sirve para comprender mejor el presente y adaptarse a él. También hay que agregar que los migrantes conllevan lazos de su tierra natal, pero la convivencia en comunidad permite el sustento de prácticas culturales compartidas y valoradas positivamente. En este sentido, de acuerdo con Penna (2006: 97), "se habla de raíces que se relacionan con una referencia espacial (territorial o cultural) y que se pierden con la migración, aunque las prácticas culturales no dependen tan directamente de la permanencia en el país de origen", dado que los lugares son fluidos y pueden conservarse en otros espacios, recuperarse de la memoria o recrearse.

Pertenecer a un territorio implica mucho más que nacer y vivir en él. Implica, sobre todo, establecer relaciones sociales y construir una identidad regional de la misma 
forma en la que el dominio de la lengua y la creación de lazos sociales no implica, necesariamente, la existencia de un sentido de pertenencia (PIOVESAN, 2020). Sentirse parte de un lugar significa construir una identidad cultural, y eso incluye hábitos, creencias y tradiciones vinculadas a la vida cotidiana.

Regresemos a la afirmación de Hall (2012) sobre el hecho de que las identidades no definen individuos o grupos étnicos específicos, sino que se negocian discursivamente en las interacciones con los demás. En tiempos más recientes, nos enfrentamos a culturas híbridas donde existe un doble sentido de pertenencia, que orienta las relaciones individuales y colectivas y da nuevas formas a la sociedad. Para Penna (2006), la construcción de las identidades está estrechamente ligada a las condiciones de existencia, a la cultura y a las relaciones sociales, que se vuelven flexibles mediante la manipulación de los referentes disponibles en la sociedad en la que vive el individuo en un momento histórico determinado, disponibles conforme a la posición quel individuo ocupa y a las prácticas sociales que desarrolla.

Otros corotopónimos retoman espacios más cercanos del mismo estado y no siempre habitados por los denominadores, como São Felix de Balsas, Feira Nova, Nova Colinas, Estreito, Alto Parnaíba, Benedito Leite, Loreto, São Domingo do Azeitão, Açailândia, Grajaú, Imperatriz, Sítio Novo, Maranhão, Mearim; o fuera del estado: Pernambuco, Bahia, Natal, Ceara, Sergipe, Recife, Maceió, Goiás, Rio de Janeiro y Portugal, Egito, Veneza, Paraguai. En la materialización de la memoria puede verse una convergencia cultural, espontánea o negociada, en la oficialización de estos nombres, un cierto acomodo de convergencias culturales que se reflejan en el sistema lingüístico.

Cabe destacar la gran presencia de numerotopónimos, es decir, nombres de calles sin un "nombre específico", que se identifican únicamente gracias a un número, como en el Bairro Cajueiro - Rua 9 y Rua 11 - con la esperanza de que los denominadores encuentren un nombre que ayude a identificar mejor esas calles. En este caso, la denominación oficial no tomó en cuenta la motivación espontánea, sino que se usaron abstracciones que representan una cuantificación del mundo material, provocando que los topónimos en cuestión se alejaran de esas motivaciones de carácter histórico, memorístico e identitario "hasta construirse un uso nuevo para el mismo objeto, que vuelva a estar motivado o resemantizado" (DICK, 2004). El uso de estos topónimos neutros es típico de sociedades en transición y, según Hall (2014: 109), las personas no están y nunca estarán 
unificadas, porque son, irrevocablemente, el producto de múltiples historias y culturas interconectadas. Las identidades, entonces, estarían relacionadas con la cuestión del uso de recursos de la historia, la memoria, el lenguaje y la cultura para producir aquello en lo que nos hemos de convertir. Los caminos que hemos tomado son llamados por el autor "rutas", que se negocian en el discurso, surgen en la narrativización del "yo" y nos llevan a un sentido de pertenencia a través del cual las identidades emergen a partir del "cómo hemos sido representado" y "cómo esa representación afecta la forma en que podemos representarnos a nosotros mismos".

El conjunto de topónimos aquí analizados desde la perspectiva de la memoria o, aún más allá: de la historia - y la identidad recuerda el fuerte entrelazamiento de la lengua del hombre del presente con el pasado, de cómo el lenguaje está vinculado al pensamiento y cómo el pensamiento se compone de recuerdos, de memoria. Los grupos axiotoponímicos, corotoponímicos e historiotoponímicos conllevan, en su esencia, referentes que son representaciones del pasado, de la memoria, de la personificación misma de los sujetos de estos grupos de topónimos. Estos grupos dirigen el pasado hacia el momento y el lenguaje presentes, incluyen al hombre y a la tierra, las historias y los sentimientos que son apreciados por los denominadores; la (re)creación y recuperación por medio del lenguaje revelan cómo nos constituimos como sujetos sociales e históricos. El lenguaje es, quizá, el mayor instrumento de los rasgos identitarios del hombre, que está vinculado a un territorio determinado.

\section{Comentarios finales}

Estas reflexiones comprueban la forma en la que aspectos de la identidad y la memoria de los habitantes se manifiestan en la formación toponímica de los espacios de la ciudad de Balsas, al sur de Maranhão, una región que se formó por diferentes ciclos migratorios que sucedieron con mayor abundancia en la década de 1970, con la llegada de migrantes del sur, y que se intensificó con la formación de una frontera agrícola.

La ciudad resultó ser un territorio constituido por correlaciones: diferentes barrios, plazas, calles, que son elementos importantes que unen a un cierto número de personas y que posibilitan la creación de múltiples correlaciones y representaciones memorísticas e identitarias. De esta manera, se puede afirmar que las identidades se 
forman en un contexto que incluye el entorno donde vive la familia: las relaciones con amigos y vecinos en lugares que presentan una serie de significados que se generan gracias a los encuentros entre las personas. También se comprobó que la alteridad, el sincretismo y el acomodo de las convergencias son rasgos de representación que fueron vistos en los grupos de topónimos de las aglomeraciones urbanas de Balsas y que estos nombres llevan la cultura, la historia y el lugar de nacimiento de los sujetos denominadores a la materialidad de la lengua.

El hecho de que los lugares y nombres designados fueran el resultado de las experiencias humanas y las relaciones con quienes los rodean en la vida cotidiana fue visto como elemento que constituye los rasgos memorísticos de estos nombres. En este contexto, los topónimos surgen para identificar al grupo que los utiliza a través de una fuerte relación de subjetividad, marcando rasgos culturales inconfundibles, pero también estrategias de poder. Además, las nominaciones y motivaciones que hay para elegir los nombres de lugares nos permiten conocer mucho sobre el territorio y su formación y, al mismo tiempo, recuperar las memorias y construcciones identitarias del lugar.

Se observó que en las calles de Balsas hay una mayoría significativa de antropotopónimos, lo que refleja un contexto cultural específico marcado por relaciones de poder vinculadas a personalidades de clase política o a ciudadanos comunes que poseían riqueza o, incluso, a familiares de políticos. En este caso, también aparecen nombres de pioneros y nombres históricos, lo que marca la relación que los vecinos que viven o que vivieron tenían con la vida cotidiana. Algunos espacios públicos se destacaron por la imposición de nombres por parte del gobierno, pero en otros, la fuerza de la memoria popular colectiva, a través del uso cotidiano del nombre conocido, se destacó y ayudó a comprender más sobre la historia del lugar y así preservar la memoria.

La región sur de Maranhão, marcada por la mezcla de muchas personas provenientes de diferentes lugares, refleja un proceso de (re)construcción de los referentes de la vida, puesto que el concepto de identidad no puede ser esencialista, ya que la identidad social construida no es fija ni inmutable, sino que está en constante transformación. Debido a estos cambios en los procesos relacionados con la identidad social, Balsas presenta muchos topónimos indefinidos, numerotopónimos y topónimos neutros que están a la espera de un nombre. 
Finalmente, en vista de los resultados obtenidos sobre las representaciones de la identidad, la memoria y la historia de los topónimos de la ciudad de Balsas, Maranhão, es posible concluir que los nombres de los espacios urbanos son un testimonio vivo de la historia de las personas que habitan en ellos; que estos nombres son registros sensibles y descriptivos de la memoria y la identidad, y que el individuo es responsable de dirigir su historia y que puede construir nuevas identidades a lo largo de su existencia, motivado por correlaciones, fragmentaciones y rupturas, al permitir un nuevo reconocimiento en las interacciones sociales y espaciales de las que forma parte.

Recibido em 04/05/2020

Aceito em 23/05/2021

Publicado em 25/08/2021

\section{Referencias}

BERGSON, Henri. (2006). Memória e Vida. Textos escolhidos por Gilles Deleuze. Trad. Claudia Berliner. São Paulo: Martins Fontes.

BRANDÃO, Analídia dos Santos.; ABBADE Celina Márcia de Souza. (2016). Os antropotopônimos na Bahia de Todos os Santos: uma análise social e linguística. Revista GTLex, 1, n.2, 312-325

CALDO, Costantino. (1996). Geografia umana, Palermo, Palumbo.

CANEVACCI, Massimo. (1996). Sincretismo: uma exploração das hibridações culturais. Trad.: Roberta Barni. São Paulo: Instituto Cultural Ítalo Brasileiro; Instituo Italiano di Cultura.

CASTRO, Maria Célia Dias de. (2012). Maranhão: sua toponímia, sua história, $474 \mathrm{f}$. Tese (Doutorado em Linguística) - Faculdade de Letras, Universidade Federal de Goiás, Goiânia.

DICK, Maria Vicentina de Paula do Amaral. (1980). Toponímia e Antroponímia no Brasil. Coletânea de Estudos. São Paulo: Serviço de Artes Gráficas/FFLCH/USP.

DICK, Maria Vicentina de Paula do Amaral. (2004). Rede de conhecimento e campo lexical: hidrônimos e hidrotopônimos na onomástica brasileira. In: ISQUERDO, A. N.; KRIEGER, M. G. (Org.). As ciências do léxico. Lexicologia, lexicografia, terminologia. v. II. Campo Grande: UFMS, 121-130.

DICK, Maria Vicentina de Paula do Amaral. (1990). A motivação toponímica e a realidade brasileira. São Paulo, Arquivo do Estado.

DICK, Maria Vicentina de Paula do Amaral. (1992). Toponímia e antroponímia no Brasil: coletânea de estudos. 3. ed. São Paulo: FFL/USP. 
HOUAISS, Antonio. VILLAR, M. S. (2009). Dicionário Houaiss de Língua Portuguesa. Elaborado pelo Instituto Antônio Houaiss de Lexicografia e Banco de Dados da Língua Portuguesa S/C Ltda. Rio de Janeiro: Objetiva.

LE GOFF, Jacques. (2003). História e memória. Trad. Bernardo Leitão. Campinas, SP: Editora da UNICAMP.

HALL, Stuart. (2012). A identidade cultural na pós-modernidade. Rio de Janeiro: DP\&A.

HALL, Stuart. (2014). Quem precisa de identidade? In: SILVA, T. T. Identidade e diferença: a perspectiva dos estudos culturais (org.). Petrópolis: Vozes, 247-264.

MORENO, Jean Carlos. (2014). Revisitando o conceito de identidade nacional. In: RODRIGUES, Cristina Carneiro. LUCA, Tania Regina de. GUIMARÃES, Valéria. orgs. Identidades brasileiras: composições e recomposições [online]. São Paulo: Editora UNESP; São Paulo: Cultura Acadêmica, 7-29. Desafios Contemporâneos collection. ISBN 978-85-7983-515-5.

NORA, Pierre. (1993). Entre memória e história: a problemática dos lugares. Trad. Yara Aun Khoury. In.: Revista do programa de estudos pós-graduados em história e do departamento de história - Projeto história, 10, PUC/SP.

PENNA, Maura. (2006). Relatos de migrantes: questionando as noções de perda de identidade e desenraizamento. In: SIGNORINI, Inês. (org.). Lingua(gem) e identidade. Campinas: Mercado das Letras, 89-111.

PIOVESAN, Marta Helena Facco. (2020). A construção de identidades: (des)encontros no sul do Maranhão. Curitiba: CRV.

PHILIPPSEN, Neusa Inês. LIMA, José Leonildo. (2018). Diversidade e Variação Linguística em Mato Grosso, Cáceres: Editora Unemat.

POLLAK, Michael. (1992). Memória e Identidade Social. Estudos Históricos, Rio de Janeiro, vol. 5, 10, 200-212.

SAPIR, Edward. (1980). A Linguagem. São Paulo: Perspectiva.

SANDRI, Márcia Meurer. BAÚ, Sandra. Cristina Schuster. (2008). Balsas, palco de integração social: o encontro do sertanejo e do gaúcho. Imperatriz-MA: Ética.

SANTOS, Luiz Eduardo Neves dos. (2020). Toponímia e Lugar: os significados múltiplos dos logradouros públicos no município de Grajaú, MA. Caderno de Geografia, 30,62 .

SEABRA, Maria Cândida Trindade Costa de. (2004). A formação e a fixação da Língua Portuguesa em Minas Gerais: a toponímia da Região do Carmo. Tese de Doutorado, UFMG: Belo Horizonte. 
Onomástica Desde América Latina, n.4, v.2, jul - dez, 2021, p. 176-199. ISSN 2675-2719

https://doi.org/10.48075/odal.v0i0.28006

TEIS Denize Terezinha. SEIDE Marcia Seide. LUCAS Patrícia (2018) Os topônimos na paisagem linguística da Av. Zelina em São Paulo: um encontro na interdisciplinaridade. Revista do GELNE. 20 (2), 16-29.

TOSI, Renzo. (1996). Dicionário de sentenças latinas e gregas. (tradução Ivone Castilho Benedetti) São Paulo: Martins Fontes. 